\title{
Thyroid Autoimmunity in the Context of Type 2 Diabetes Mellitus: Implications for Vitamin D
}

\author{
Konstantinos Toulis, ${ }^{1}$ Xanthippi Tsekmekidou, ${ }^{1}$ Evangelos Potolidis, ${ }^{1}$ \\ Triantafyllos Didangelos, ${ }^{2}$ Anna Gotzamani-Psarrakou, ${ }^{3}$ Pantelis Zebekakis, ${ }^{1}$ \\ Michael Daniilidis, ${ }^{4}$ John Yovos, ${ }^{1}$ and Kalliopi Kotsa ${ }^{1}$ \\ ${ }^{1}$ Diabetes Center, Department of Endocrinology and Metabolism, AHEPA University Hospital, 54636 Thessaloniki, Greece \\ ${ }^{2}$ First Propaedeutic Department of Internal Medicine, AHEPA University Hospital, 54636 Thessaloniki, Greece \\ ${ }^{3}$ Laboratory of Nuclear Medicine, AHEPA University Hospital, 54636 Thessaloniki, Greece \\ ${ }^{4}$ First Department of Medicine, AHEPA University Hospital, 54636 Thessaloniki, Greece \\ Correspondence should be addressed to Kalliopi Kotsa; kalli@med.auth.gr
}

Received 21 October 2014; Accepted 29 December 2014

Academic Editor: David Leslie

Copyright (C) 2015 Konstantinos Toulis et al. This is an open access article distributed under the Creative Commons Attribution License, which permits unrestricted use, distribution, and reproduction in any medium, provided the original work is properly cited.

\begin{abstract}
Vitamin D deficiency has been associated with both type 2 diabetes mellitus (T2DM) and autoimmune disorders. The association of vitamin D with T2DM and thyroid autoimmunity (TAI) has not been investigated. Thus, we aimed to explore the putative association between T2DM and thyroid autoimmunity (TAI) focusing on the role of 25-hydroxy-vitamin D (25(OH)D). Study population included $264 \mathrm{~T} 2 \mathrm{DM}$ patients and 234 controls. To explore the potential association between $25(\mathrm{OH}) \mathrm{D}$ and thyroid autoimmunity while controlling for potential confounders-namely, age, gender, body mass index, and presence of T2DMmultivariate logistic regression analyses were undertaken. Patients with T2DM were younger $(P<0.001)$ and had significantly lower 25(OH)D levels $(P<0.001)$ and higher anti-TPO titers $(P=0.005)$. Multivariable logistic regression analyses suggested that T2DM and 25(OH)D levels were significantly associated with the presence of thyroid autoimmunity. In an elderly population of diabetic patients and controls with a high prevalence of vitamin D deficiency/insufficiency, a patient with T2DM was found to be 2.5 times more likely to have thyroid autoimmunity compared to a nondiabetic individual and the higher the serum $25(\mathrm{OH}) \mathrm{D}$ levels were, the higher this chance was.
\end{abstract}

\section{Introduction}

The association between type 2 diabetes mellitus (T2DM) and the presence of thyroid autoimmunity (TAI) has been a matter of debate. Although earlier reports dismissed any link between them [1-3], there is evidence to suggest an increased prevalence of TAI in patients with T2DM $[4,5]$. Considering the discordant results, the direct association between TAI and newly identified hypothyroidism in the context of T2DM [6], and evidence implying a detrimental role for hypothyroidism in insulin sensitivity [7], it could be advocated that the association between T2DM and TAI requires further clarification from both the clinical and research perspectives.
Vitamin D, beyond its pivotal role in the regulation of calcium and phosphate homeostasis, emerges as a potentially important coregulator of both autoimmunity $[8,9]$ and insulin sensitivity $[10,11]$. Vitamin D is considered to promote Th2 over Th1 immune response phenotype [12] acting through the vitamin D receptor- (VDR-) expressing immune cells $[12,13]$, while influencing both insulin secretion and sensitivity acting at the level of pancreatic beta-cells and muscle cells $[10,14]$.

In general, vitamin $\mathrm{D}$ deficiency or insufficiency is thought to be a predisposing factor to both autoimmune disorders and glucose intolerance. This preliminary evidence might provide the biological background to suggest that vitamin $\mathrm{D}$ could be involved in the putative association 
between T2DM and TAI; however, such hypothesis has not been addressed in the literature as yet.

To this end, we aimed to explore the association between T2DM and TAI focusing on the role of $25(\mathrm{OH}) \mathrm{D}$ in an ethnically homogenous, elderly population, using a crosssectional, nested within case-control, study design.

\section{Materials and Methods}

Subjects with an established diagnosis of T2DM were consecutively recruited from the outpatient diabetes clinic of a tertiary reference hospital from December 2011 to March 2012. Community-dwelling individuals from the same region, in whom normal glycaemia was documented, both by fasting glucose (FPG) and glycated haemoglobin (HbAlc), were also recruited as controls during the same period. Controls were recruited from community centres providing social services to senior citizens (KAPI, Open Centres for the Protection of the Elderly). Current use of corticosteroids served as an exclusion criterion, since this could act as a confounder both at the levels of autoimmunity and glucose homeostasis. Subjects under vitamin D supplementation were also excluded from the study. At the day of the recruitment, a structured medical interview and a physical examination were performed in each subject, medical records were retrieved, and blood samples were drawn and stored at $-80^{\circ} \mathrm{C}$. Informed consent was provided and the study was conducted in accordance with the Declaration of Helsinki. Descriptive characteristics of the study population are summarized in Table 1.

2.1. Measurements. 25-Hydroxy-vitamin D (25(OH)D), glycated haemoglobin (HbAlc), autoantibodies against thyroid peroxidase (TPOab) and thyroglobulin (TGab), and thyroidstimulating hormone (TSH) were determined for each subject. Radioimmunoassays (DiaSorin, RIA) were performed according to the manufacturer's instructions for the measurements of serum $25(\mathrm{OH}) \mathrm{D}$ (intra-assay coefficient of variation $(\mathrm{CV}): 5.19 \%$, interassay $\mathrm{CV}: 7.90 \%$, and detection limit: $4 \mathrm{ng} / \mathrm{mL}$ ) and thyroid parameters (TPOab intra-assay CV: $4.1 \%$, interassay CV: $9.1 \%$, and detection limit: $0.8 \mathrm{U} / \mathrm{mL}$ and TGab intra-assay CV: $2.9 \%$, interassay CV: $11.6 \%$, and detection limit: $6 \mathrm{U} / \mathrm{mL}$ ). HbAlc measurements were performed by a standardized high performance liquid chromatography (HPLC) assay.

2.2. Definitions. A subject was included in the control group (subjects without diabetes) if FPG was less than $7.0 \mathrm{mmol} / \mathrm{L}$ $(126 \mathrm{mg} / \mathrm{dL})$ and $\mathrm{HbAlc}$ less than $48 \mathrm{mmol} / \mathrm{mol}(6.5 \%)$ and no use of diabetes medications was reported. A subject was designated as TAI positive if either TPOab or TGab was higher than $100 \mathrm{U} / \mathrm{mL}$ and as vitamin $\mathrm{D}$ deficient/insufficient if $25(\mathrm{OH}) \mathrm{D}$ was below $75 \mathrm{nmol} / \mathrm{L}(30 \mathrm{ng} / \mathrm{mL})$. Presence of hypothyroidism was documented by a TSH value greater than $4.0 \mathrm{mU} / \mathrm{L}$ or thyroxine treatment.

2.3. Statistical Analysis. Continuous and dichotomous variables were described as mean (standard deviation) or $n(\%)$, respectively. Normality assumption was assessed by visual inspection of the distribution as well as the KolmogorovSmirnov test. Differences in means were explored using Mann-Whitney and chi-squared tests for continuous and dichotomous variables, respectively. To explore the potential association between $25(\mathrm{OH}) \mathrm{D}$ and thyroid autoimmunity while controlling for potential confounders, namely, age, gender, body mass index (BMI), and presence of T2DM, multivariate logistic regression analyses were undertaken in all study populations. Standardized values (z-scores) of the natural logarithms for all continuous variables were used. All analyses were undertaken within Stata 10.0.

\section{Results}

A total of 498 participants (264 patients with T2DM and 234 healthy controls) constituted the study population. Patients with T2DM were younger and more obese and had significantly lower 25(OH)D and higher TPOab titres compared to controls (Table 1). Prevalence of hypothyroidism was comparable between groups; however the prevalence of thyroid autoimmunity was approximately twofold greater in patients with T2DM compared to controls. Interestingly, the great majority of the study population $(78 \%)$ was found to be $25(\mathrm{OH}) \mathrm{D}$ deficient or insufficient and the prevalence of vitamin $\mathrm{D}$ deficiency/insufficiency was significantly higher in patients with T2DM compared to controls. This finding was robust when a lower threshold for $25(\mathrm{OH}) \mathrm{D}(50 \mathrm{nmol} / \mathrm{L}$ $(20 \mathrm{ng} / \mathrm{mL}), 65.5 \%$ versus $47 \%$ in patients with T2DM and controls, resp., and chi2 $P$ value $<0.001)$ was applied. $25(\mathrm{OH}) \mathrm{D}$ levels by study group and TAI status are presented in Figure 1.

Multivariable logistic regression analyses adjusting for age, gender, and body mass index suggested that both the presence of T2DM (odds ratio (OR): $3.31,95 \%$ confidence interval (CI): 1.58-6.90) and 25(OH)D levels (OR: 1.32, 95\% CI: 1.01-1.72) were significantly associated with the presence of TAI (Table 2). Interpreting this finding in clinical terms, each unit increase in $25(\mathrm{OH}) \mathrm{D}$ levels (in standard deviations, corresponding to approximately $30 \mathrm{nmol} / \mathrm{L}(12 \mathrm{ng} / \mathrm{mL})$ in the study population) is associated with a $30 \%$ increase (in odds) for TAI. $25(\mathrm{OH}) \mathrm{D}$ is depicted in $\mathrm{ng} / \mathrm{mL}$.

\section{Discussion}

In an elderly population of patients with T2DM and controls with a high prevalence of vitamin D deficiency/insufficiency, T2DM and 25(OH)D levels were significantly associated with TAI. The association between $25(\mathrm{OH}) \mathrm{D}$ and TAI was noted only in the presence of T2DM and, interestingly, it was found to be positive. Conflicting results have been reported in the literature regarding the association between T2DM and TAI [1-7]. These contradictory findings might either reflect T2DM phenotypic heterogeneity or result from the limited statistical power, multiple confounders, uncontrolled design, and ethnic heterogeneity in individual studies. We hypothesized that this inconsistency might imply a role for vitamin $\mathrm{D}$ in light of evidence suggesting its potential link to both thyroid autoimmunity and glucose intolerance 
TABLE 1: Descriptive characteristics of the study population.

\begin{tabular}{|c|c|c|c|}
\hline & Normal & Type 2 diabetes mellitus & $P$ \\
\hline$N$ & 234 & 264 & \\
\hline Male gender (female) & $89(38)$ & $109(41)$ & NS \\
\hline Age (years) & $72.2(6.5)$ & $67.6(9.7)$ & 0.0001 \\
\hline Body mass index $\left(\mathrm{kg} / \mathrm{m}^{2}\right)$ & $30.6(4.9)$ & $31.6(5.7)$ & 0.032 \\
\hline Type 2 diabetes mellitus duration (years) & N/A & $10.0(8.4)$ & \\
\hline Glycated haemoglobin (\%) & $4.7(0.5)$ & $7.1(1.5)$ & 0.0001 \\
\hline 25-Hydroxy-vitamin D (ng/mL) & $22.6(12.6)$ & $16.5(10.4)$ & 0.0001 \\
\hline Presence of vitamin D deficiency/insufficiency & $172(73.5 \%)$ & $215(81.4)$ & 0.04 \\
\hline Thyroid peroxidase $\mathrm{Ab}(\mathrm{IU} / \mathrm{mL})$ & $60(156)$ & $90(200)$ & 0.005 \\
\hline Thyroglobulin Ab (IU/mL) & $44(131)$ & $54(136)$ & NS \\
\hline Thyroid autoimmunity & $18(7.7)$ & $38(14.4)$ & 0.018 \\
\hline Thyroid stimulating hormone $(\mu \mathrm{IU} / \mathrm{mL})$ & $1.95(1.60)$ & $2.25(3.64)$ & NS \\
\hline Hypothyroidism & $8(3.4)$ & $11(4.2)$ & NS \\
\hline
\end{tabular}

Data presented as mean (standard deviation) or $N(\%)$. $P$ values refer to Mann-Whitney test or Pearson chi-square. NS: nonsignificant at the level of 0.05. Abs: autoantibodies.

TABLE 2: Multivariable logistic regression using thyroid autoimmunity as the dependent variable.

\begin{tabular}{lccc}
\hline Covariates & Odds ratio & $95 \%$ CI & $P$ \\
\hline Type 2 diabetes mellitus & 3.31 & $1.58-6.90$ & 0.001 \\
Gender & 0.64 & $0.35-1.18$ & NS \\
Age & 0.97 & $0.26-3.55$ & NS \\
Body mass index & 1.24 & $0.89-1.72$ & NS \\
25-Hydroxy-vitamin D & 1.32 & $1.01-1.72$ & 0.047 \\
\hline
\end{tabular}

CI: confidence interval.

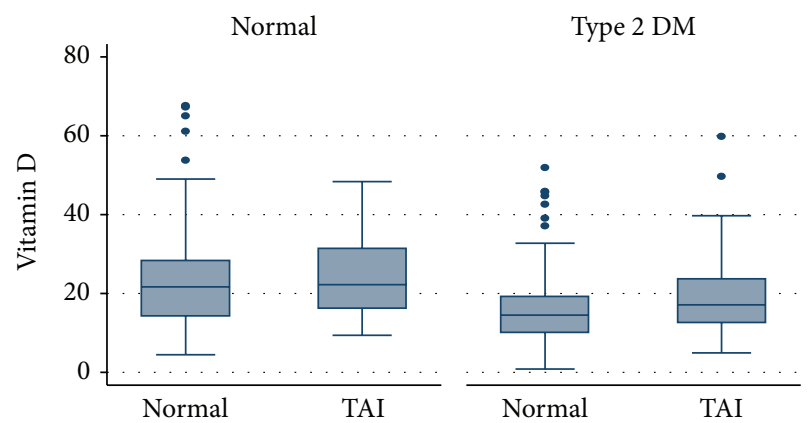

FIGURE 1: Box-plot representing serum 25-hydroxy-vitamin D levels by study group and thyroid autoimmunity status.

individually. In specific, it has been reported that allelic variations within the VDR gene may mediate susceptibility to thyroid autoimmunity $[15,16]$. Vitamin D insufficiency has been associated with thyroid autoimmunity [17], serum $25(\mathrm{OH}) \mathrm{D}$ levels were found to be significantly lower in patients with thyroid autoimmunity compared to controls $[18,19]$, and the severity of $25(\mathrm{OH}) \mathrm{D}$ deficiency correlated with thyroid antibody levels in both adult $[18,19]$ and children populations [20]. However, VDR knockout mice did not differ in parameters of thyrocyte function and morphology compared to wild-type controls [21], the prevalence of thyroid autoimmunity did not differ between subjects stratified on the basis of 25(OH)D levels [22], and vitamin D status was not associated with thyroid autoimmunity after controlling for sex and age [23]. Furthermore, euthyroid subjects with documented genetic susceptibility for developing thyroid autoimmunity did not differ in $25(\mathrm{OH}) \mathrm{D}$ levels compared to controls at baseline, which was also the case in those who finally developed de novo TPOAb compared to controls, questioning the role of vitamin $\mathrm{D}$ at least during the early stages of thyroid autoimmunity [24].

Similarly, a higher prevalence of vitamin D deficiency has been reported in the presence of T2DM [25] and an inverse association between circulating $25(\mathrm{OH}) \mathrm{D}$ levels and risk of incident T2DM was documented (each $10 \mathrm{ng} / \mathrm{mL}$ increment in $25(\mathrm{OH}) \mathrm{D}$ levels was associated with a $4 \%$ lower risk of T2DM) [26]. It should be noted though that this association has been recently questioned when taking into account genetic determinants [27] and that vitamin D3 supplementation had no beneficial effect on glycaemic indices in healthy overweight or obese women [28]. Collectively, it could be extrapolated that these data suggest that any role vitamin $\mathrm{D}$ might have in the putative association between thyroid autoimmunity and T2DM would be complex and certainly not self-evident. In fact, our findings seem to corroborate this notion. First, the association between thyroid autoimmunity and T2DM was documented adjusting for the major confounders; a subject with T2DM is 2.5 more likely (in odds) to have thyroid autoimmunity compared to a normal individual. Second, vitamin D levels are significantly associated with the presence of thyroid autoimmunity in subjects with T2DM, but not in controls. Third, it was shown that the higher the serum $25(\mathrm{OH}) \mathrm{D}$ levels are in these patients, the higher the chance was for thyroid autoimmunity. The latter finding is counterintuitive and of borderline statistical significance; therefore it requires further confirmation in subsequent studies. Of note, when 25(OH)D levels were modeled as a categorical variable, this association was not robust and no threshold effect was documented. Patients 
with T2DM have statistically significant higher percentage of thyroid autoimmunity compared to controls (Table 1). Of note, both groups have a high prevalence of vitamin $\mathrm{D}$ deficiency/insufficiency and the difference between the two groups is marginally statistically significant. On the other hand, it was found that TAI is more prevalent when the levels of vitamin D are higher. Vitamin D is one among many factors that could potentially modify thyroid autoimmunity. This discrepant finding should be attributed to the confounding effect of age, BMI, and gender, namely, all variables used in the multivariable regression analysis. This is why we undertook a regression analysis, adjusting for potential confounders. Any inferences were based on the findings of the latter analysis. In this model of regression analysis, both vitamin $\mathrm{D}$ levels and T2DM were included as covariates although associated. However, the degree of correlation between T2DM and 25(OH)D levels in our sample was not as high as to undermine the analysis. In any case, the theoretical risk of multicollinearity overinflates standard errors. Thus, there would be a risk of an insignificant finding. This was not the case in our study with regard to vitamin $\mathrm{D}$.

Since the complex interplay between thyroid autoimmunity and vitamin $\mathrm{D}$ in the context of T2DM has not been explored to date, it might be premature to suggest an alternative hypothesis before further confirmation nor could it be substantiated on the basis of our data or study design. However, it might be intriguing to hypothesize that the effects noted in our study might be compatible with a tissue-specific model in the action of vitamin D on autoimmunity. Possible immunomodulatory effects of vitamin $\mathrm{D}$ include inhibition of proinflammatory activity of CD4+ Th1 cells and their production of cytokines (interleukin 2 (IL-2), interferon(IFN-) $\gamma$, and tumor necrosis factor- $\alpha$ [29]).

In addition to its anti-inflammatory effects, vitamin D also promotes Th2 responses by enhancing IL-4, IL-5, and IL-10 production, thus promoting a more anti-inflammatory phenotype (Th2 state) of the $\mathrm{T}$ cell compartment over the inflammatory Th1 state [12]. On the other hand, the formation of thyroid autoantibodies by thyroid-infiltrating lymphocytes and blood lymphocytes has been found to be a distinct procedure. Although the intrathyroidal process is characterized by a shift towards Thl, the stimulus inducing the formation of thyroid autoantibodies by blood lymphocytes commonly shifts the balance towards Th2. Therefore, immune deviation towards Th2 has long been questioned as appropriate therapy for autoimmune thyroid disorders and has even been suggested that it "could project the patient from the frying pan into the fire" [30]. It is obvious that the above hypothesis requires further experimental confirmation.

Considering the observational nature of the evidence and, thus, the inappropriateness for causality inference, caution is advisable in the interpretation of the findings. Notably, the study findings should not be extrapolated to different populations with different baseline characteristics. Our sample demonstrated significant prevalence of vitamin D deficiency and a higher prevalence of thyroid autoimmunity in patients with T2DM compared to controls. Both of these sample characteristics are consistent with previous reports $[31,32]$, thus reassuring external validity concerns. It should also be noted that oral glucose tolerance test was not performed for the diagnosis of diabetes mellitus and, thus, a marginal misclassification of patients with diabetes as controls could not be excluded.

However, the impact of limitation on the study findings is probably minimal, since the discrimination between the diabetic and control groups was performed on the basis of two glycemic indices (fasting glucose and HbAlc measurements), which secured a clear distinction between groups. Similarly, the potential confounding effect of seasonal variation in serum $25(\mathrm{OH}) \mathrm{D}$ levels [33] is also expected to be minimal, since the collection of blood samples was performed during the same season (winter).

\section{Conclusions}

In summary, in an elderly population of patients with T2DM and controls with a high prevalence of vitamin $\mathrm{D}$ deficiency/insufficiency, it was shown that T2DM and vitamin $\mathrm{D}$ were associated with TAI. A patient with T2DM was 2.5 times more likely (in odds) to have thyroid autoimmunity compared to a normal individual and the higher the serum $25(\mathrm{OH}) \mathrm{D}$ levels were, the higher the chance for thyroid autoimmunity was.

\section{Conflict of Interests}

The authors declare that there is no conflict of interests regarding the publication of this paper.

\section{Acknowledgment}

The authors would like to thank the Hellenic Diabetes Association for funding in part this study.

\section{References}

[1] C. Cardoso, A. E. Ohwovoriole, and S. F. KuKu, "A study of thyroid function and prevalence of thyroid autoantibodies in an African diabetic population," Journal of Diabetes and its Complications, vol. 9, no. 1, pp. 37-41, 1995.

[2] S. Kasim and A. Bessman, "Thyroid autoimmunity in Type 2 (non-insulin-dependent) diabetic patients of Caucasoid, black and Mexican origin," Diabetologia, vol. 27, no. 1, pp. 59-61, 1984.

[3] A.-R. M. Radaideh, M. K. Nusier, F. L. Amari et al., "Thyroid dysfunction in patients with type 2 diabetes mellitus in Jordan," Saudi Medical Journal, vol. 25, no. 8, pp. 1046-1050, 2004.

[4] Z. Schroner, I. Lazurova, and J. Petrovicova, "Autoimmune thyroid diseases in patients with diabetes mellitus," Bratislavské Lekárske Listy, vol. 109, no. 3, pp. 125-129, 2008.

[5] T. Yasmin, F. Ghafoor, T. Malik, R. Naz S, and A. U. Khan, "Pattern of thyroid autoimmunity in type 1 and type 2 diabetics," Journal of the College of Physicians and Surgeons Pakistan, vol. 16, no. 12, pp. 751-754, 2006.

[6] J. J. Díez and P. Iglesias, "An analysis of the relative risk for hypothyroidism in patients with Type2 diabetes," Diabetic Medicine, vol. 29, no. 12, pp. 1510-1514, 2012. 
[7] L. H. Duntas, J. Orgiazzi, and G. Brabant, "The interface between thyroid and diabetes mellitus," Clinical Endocrinology, vol. 75, no. 1, pp. 1-9, 2011.

[8] N. Agmon-Levin, M. Blank, G. Zandman-Goddard et al., "Vitamin D: an instrumental factor in the anti-phospholipid syndrome by inhibition of tissue factor expression," Annals of the Rheumatic Diseases, vol. 70, no. 1, pp. 145-150, 2011.

[9] Y. Arnson, H. Amital, N. Agmon-Levin et al., "Serum 25$\mathrm{OH}$ vitamin $\mathrm{D}$ concentrations are linked with various clinical aspects in patients with systemic sclerosis: a retrospective cohort study and review of the literature," Autoimmunity Reviews, vol. 10, no. 8, pp. 490-494, 2011.

[10] C. M. Girgis, R. J. Clifton-Bligh, M. W. Hamrick, M. F. Holick, and J. E. Gunton, "The roles of vitamin D in skeletal muscle: form, function, and metabolism," Endocrine Reviews, vol. 34, no. 1, pp. 33-83, 2013.

[11] J.-C. Souberbielle, J.-J. Body, J. M. Lappe et al., "Vitamin D and musculoskeletal health, cardiovascular disease, autoimmunity and cancer: recommendations for clinical practice," Autoimmunity Reviews, vol. 9, no. 11, pp. 709-715, 2010.

[12] A. Boonstra, F. J. Barrat, C. Crain, V. L. Heath, H. F. J. Savelkoul, and A. O'Garra, "1 $\alpha, 25$-Dihydroxyvitamin D3 has a direct effect on naive $\mathrm{CD} 4^{+} \mathrm{T}$ cells to enhance the development of Th2 cells," The Journal of Immunology, vol. 167, no. 9, pp. 4974-4980, 2001.

[13] G. Penna and L. Adorini, " $1 \alpha, 25$-dihydroxyvitamin D3 inhibits differentiation, maturation, activation, and survival of dendritic cells leading to impaired alloreactive T cell activation," Journal of Immunology, vol. 164, no. 5, pp. 2405-2411, 2000.

[14] T. Takiishi, C. Gysemans, R. Bouillon, and C. Mathieu, "Vitamin D and diabetes," Endocrinology and Metabolism Clinics of North America, vol. 39, no. 2, pp. 419-446, 2010.

[15] W. Horst-Sikorska, M. Ignaszak-Szczepaniak, M. Marcinkowska, M. Kaczmarek, M. Stajgis, and R. Slomski, "Association analysis of vitamin $\mathrm{D}$ receptor gene polymorphisms with bone mineral density in young women with Graves' disease," Acta Biochimica Polonica, vol. 55, no. 2, pp. 371-380, 2008.

[16] M. Stefanic, S. Papic, M. Suver, L. Glavas-Obrovac, and I. Karner, "Association of vitamin D receptor gene 3 ' -variants with Hashimoto's thyroiditis in the Croatian population," International Journal of Immunogenetics, vol. 35, no. 2, pp. 125-131, 2008.

[17] G. Tamer, S. Arik, I. Tamer, and D. Coksert, "Relative vitamin D insufficiency in Hashimoto's thyroiditis," Thyroid, vol. 21, no. 8, pp. 891-896, 2011.

[18] N. C. Bozkurt, B. Karbek, B. Ucan et al., "The association between severity of vitamin D deficiency and Hashimoto's thyroiditis," Endocrine Practice, vol. 19, no. 3, pp. 479-484, 2013.

[19] S. Kivity, N. Agmon-Levin, M. Zisappl et al., "Vitamin D and autoimmune thyroid diseases," Cellular \& Molecular Immunology, vol. 8, no. 3, pp. 243-247, 2011.

[20] O. M. Çamurdan, E. Döğer, A. Bideci, N. Çelik, and P. Cinaz, "Vitamin D status in children with Hashimoto thyroiditis," Journal of Pediatric Endocrinology and Metabolism, vol. 25, no. 5-6, pp. 467-470, 2012.

[21] I. Clinckspoor, A. C. Gérard, J. van Sande et al., "The vitamin D receptor in thyroid development and function," European Thyroid Journal, vol. 1, no. 3, pp. 168-175, 2012.

[22] R. Goswami, R. K. Marwaha, N. Gupta et al., "Prevalence of vitamin D deficiency and its relationship with thyroid autoimmunity in Asian Indians: a community-based survey," British Journal of Nutrition, vol. 102, no. 3, pp. 382-386, 2009.
[23] L. O. Chailurkit, W. Aekplakorn, and B. Ongphiphadhanakul, "High vitamin D status in younger individuals is associated with low circulatingthyrotropin," Thyroid, vol. 23, no. 1, pp. 25-30, 2013.

[24] G. Effraimidis, K. Badenhoop, J. G. P. Tijssen, and W. M. Wiersinga, "Vitamin D deficiency is not associated with early stages of thyroid autoimmunity," European Journal of Endocrinology, vol. 167, no. 1, pp. 43-48, 2012.

[25] T. L. van Belle, C. Gysemans, and C. Mathieu, "Vitamin D and diabetes: the odd couple," Trends in Endocrinology and Metabolism, vol. 24, no. 11, pp. 561-568, 2013.

[26] Y. Song, L. Wang, A. G. Pittas et al., "Blood 25-hydroxy vitamin $\mathrm{D}$ levels and incident type 2 diabetes: a meta-analysis of prospective studies," Diabetes Care, vol. 36, no. 5, pp. 1422$1428,2013$.

[27] B. Buijsse, H. Boeing, F. Hirche et al., "Plasma 25-hydroxyvitamin D and its genetic determinants in relation to incident type 2 diabetes: a prospective case-cohort study," European Journal of Epidemiology, vol. 28, no. 9, pp. 743-752, 2013.

[28] A. Salehpour, F. Shidfar, F. Hosseinpanah, M. Vafa, M. Razaghi, and F. Amiri, "Does vitamin D3 supplementation improve glucose homeostasis in overweight or obese women? A doubleblind, randomized, placebo-controlled clinical trial," Diabetic Medicine, vol. 30, no. 12, pp. 1477-1481, 2013.

[29] M. Cippitelli and A. Santoni, "Vitamin D3: a transcriptional modulator of the interferon-gamma gene," European Journal of Immunology, vol. 28, no. 10, pp. 3017-3030, 1998.

[30] J. Guo, B. Rapoport, and S. M. McLachlan, "Balance of Th1/Th2 cytokines in thyroid autoantibody synthesis in vitro," Autoimmunity, vol. 30, no. 1, pp. 1-9, 1999.

[31] A. Tsagari, K. A. Toulis, P. Makras, K. Skagias, A. Galanos, and G. Lyritis, "Performance of the mini nutritional assessment score in the detection of vitamin D status in an elderly Greek population," Hormone and Metabolic Research, vol. 44, no. 12, pp. 896-899, 2012.

[32] K. Vondra, J. Vrbikova, and K. Dvorakova, "Thyroid gland diseases in adult patients with diabetes mellitus," Minerva Endocrinologica, vol. 30, no. 4, pp. 217-236, 2005.

[33] V. Carnevale, S. Modoni, M. Pileri et al., "Longitudinal evaluation of vitamin D status in healthy subjects from southern Italy: seasonal and gender differences," Osteoporosis International, vol. 12, no. 12, pp. 1026-1030, 2001. 


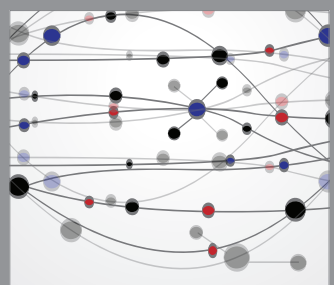

The Scientific World Journal
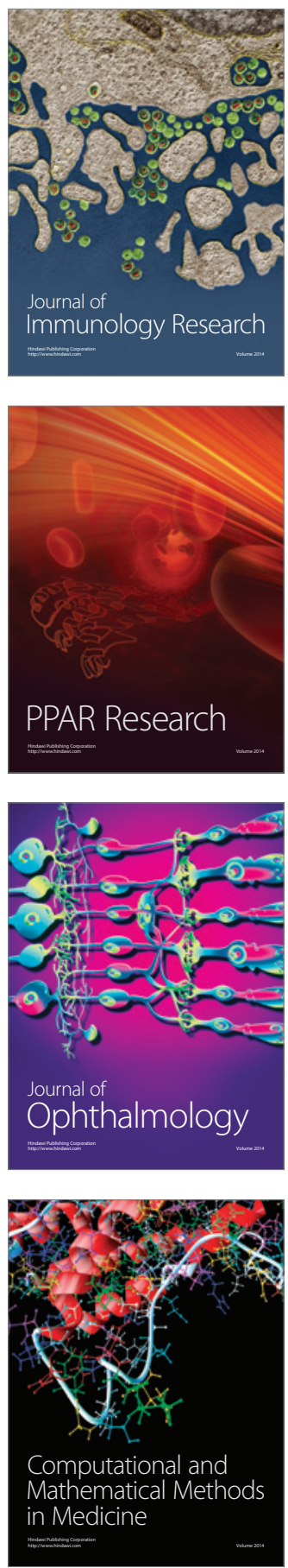

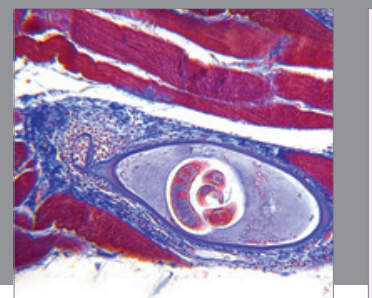

Gastroenterology

Research and Practice
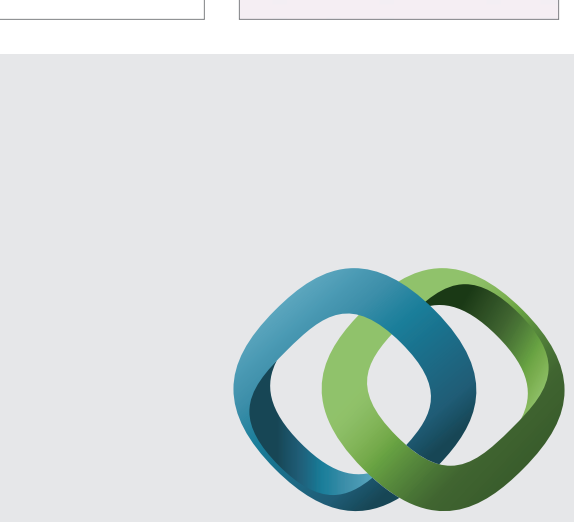

\section{Hindawi}

Submit your manuscripts at

http://www.hindawi.com
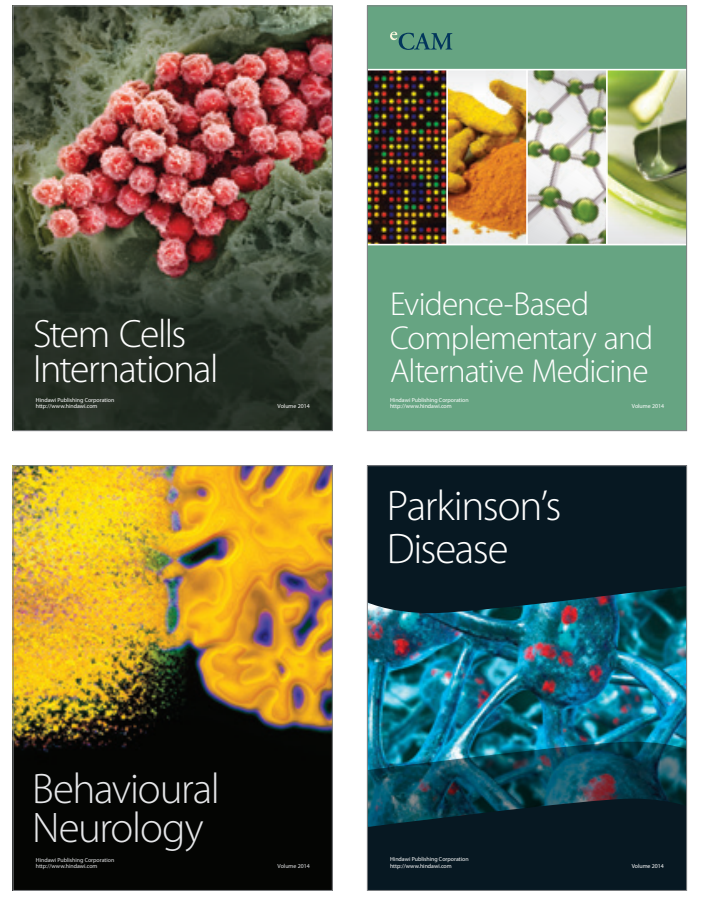
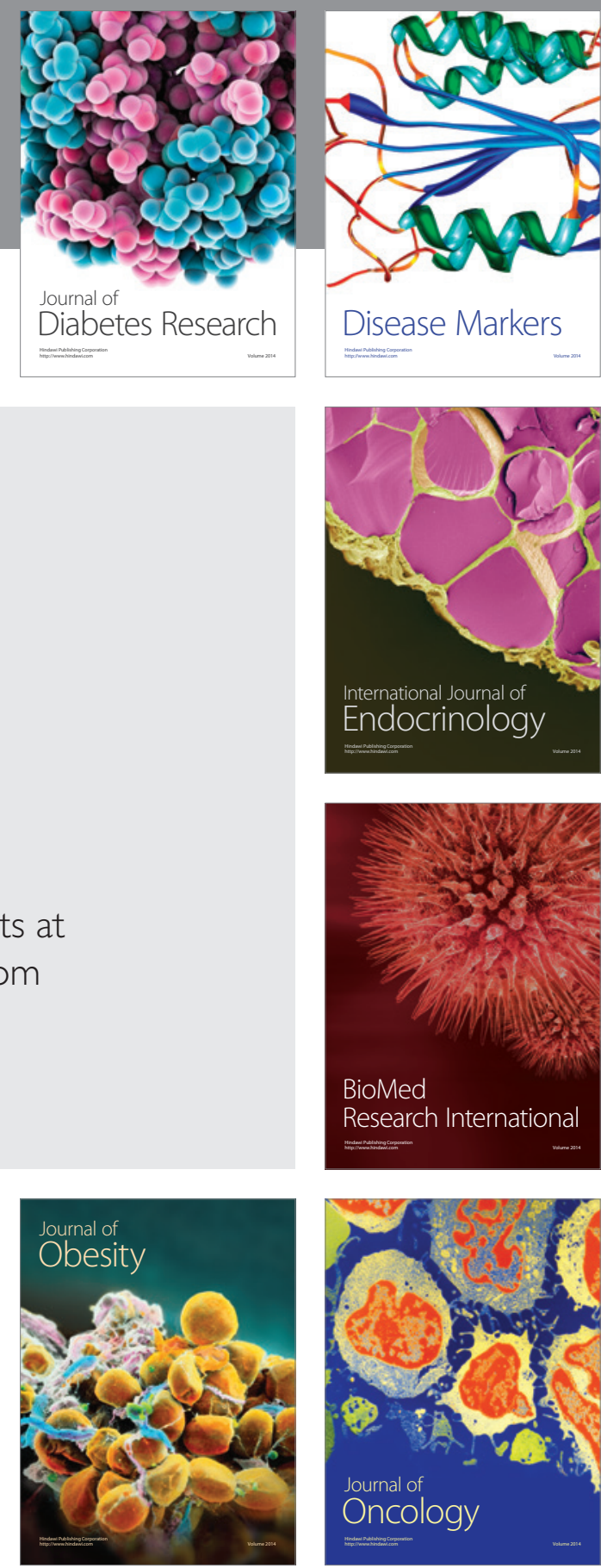

Disease Markers
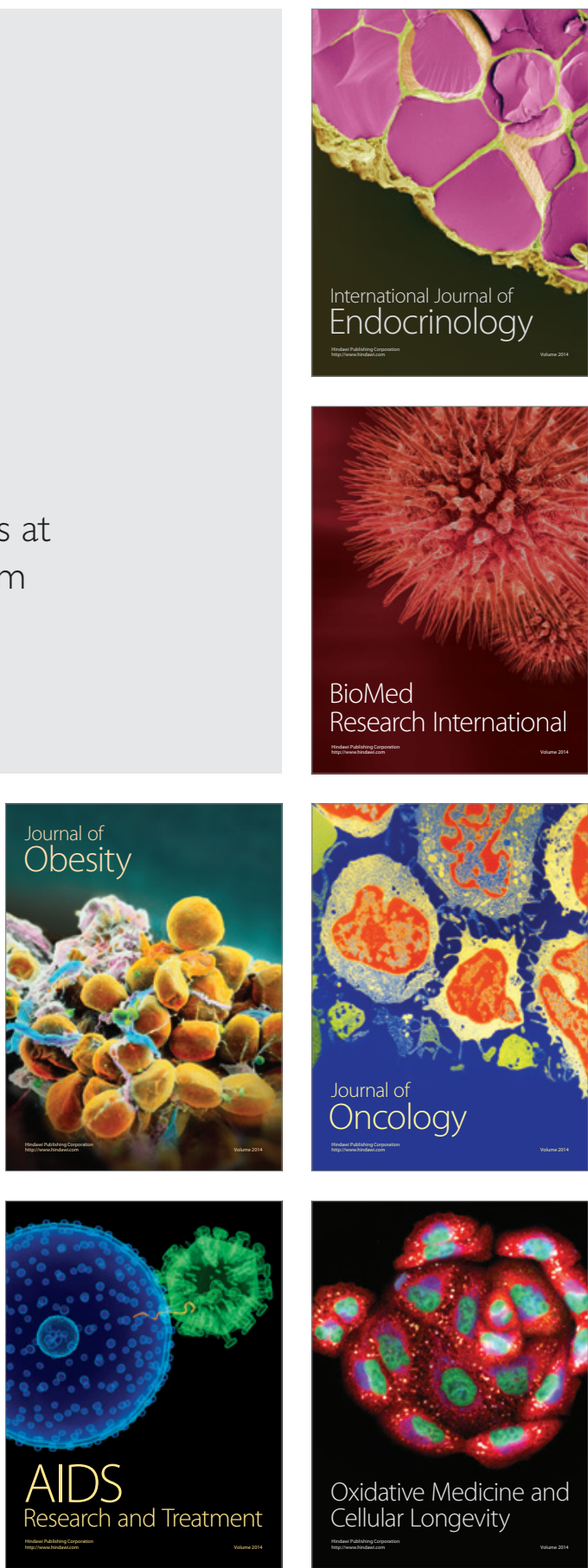